\title{
BICHO DE SETE CABEÇAS: DISCURSOS E CONSTRUÇÕES SOCIAIS SOBRE O USO DE DROGAS E A INTERNAÇÃO COMPULSÓRIA
}

\author{
${ }^{1}$ Ana Letícia Valladão Giansante \\ ${ }^{2}$ Sérgio Nojiri
}

\section{RESUMO}

O presente artigo tem como finalidade, a partir da relação entre Cinema e Direito, bem como de uma abordagem interdisciplinar, identificar os discursos e construções sociais existentes sobre as questões das drogas e da internação compulsória. Para tal fim, utilizou-se o filme "Bicho de Sete Cabeças", o qual reflete uma realidade atual e levanta problemas que precisam ser discutidos no âmbito jurídico, tendo em vista o risco de violação de direitos assegurados pela Constituição Federal. Dessa forma, busca-se realizar uma reflexão crítica sobre as temáticas e suscitar o debate com vistas à promoção de direitos de grupos socialmente estigmatizados.

Palavra-chave: "Bicho de Sete Cabeças"; Construções Sociais; Discursos; Drogas; Internação Compulsória.

\section{"BICHO DE SETE CABEÇAS": DISCOURSES AND SOCIAL CONSTRUCTIONS REGARDING THE DRUG USE AND COMPULSORY HOSPITALIZATION.}

\begin{abstract}
The purpose of this article is to identify the existing discourses and social constructions about drug issues and compulsory hospitalization, based on the relationship between Cinema and Law, as well as an interdisciplinary approach. For this purpose, was used the film "Bicho de Sete Cabeças", which reflects a current reality and raises problems that need to be discussed, in view of the risk of violation of rights guaranteed by the Federal Constitution. In this way, it is sought to critically reflect on the themes and to stimulate the debate with a view to promoting the rights of socially stigmatized groups.
\end{abstract}

Key words: "Bicho de Sete Cabeças"; Social Constructions; Discourses; Drugs; Compulsory hospitalization.

\section{INTRODUÇÃO}

\footnotetext{
${ }^{1}$ Mestranda em Desenvolvimento no Estado Democrático de Direito pela Faculdade de Direito de Ribeirão Preto da Universidade de São Paulo - FDRP/USP, São Paulo (Brasil). E-mail: ana.giansante@usp.br

${ }^{2}$ Doutor em Direito pela Pontifícia Universidade Católica - PUC, São Paulo (Brasil). Professor de Graduação e Pós-Graduação pela Faculdade de Direito de Ribeirão Preto da Universidade de São Paulo FDRP/USP, São Paulo (Brasil). E-mail: nojiri@usp.br
} 
O principal objetivo deste ensaio é realizar um debate crítico, a partir de uma abordagem interdisciplinar entre o Cinema e o Direito, a respeito dos reflexos da internação compulsória dos usuários de drogas, tendo em vista que o ordenamento jurídico brasileiro ainda traz a possibilidade da adoção de tal medida, apesar de boa parte da comunidade científica mundial se posicionar de maneira contrária à internação, como será demonstrado ao longo deste artigo.

A pesquisa foi realizada a partir do emprego de uma metodologia interdisciplinar, buscando através da interface entre direito, psicologia, medicina e arte especificamente o cinema -, novos horizontes para o debate e para os problemas emergentes no mundo jurídico. Assim, usa-se o cinema como um meio de representar uma realidade concreta e trazer à discussão o tema em comento, englobando elementos de outras áreas do conhecimento para aprimorar o debate e ir além da mera prescrição legal.

A investigação do tema foi realizada mediante o cotejo de alguns pontos do ordenamento jurídico brasileiro e de estudos existentes sobre as drogas e a internação compulsória, em um movimento dialético com as cenas e questionamentos trazidos pelo filme. Assim, a partir problemática apresentada na obra cinematográfica Bicho de Sete Cabeças, que aborda a questão da internação compulsória de maneira crítica, narrando diversos aspectos relacionados a tal medida, pretende-se analisar as questões inerentes à temática e a tutela de direitos constitucionalmente assegurados.

No desenvolvimento do presente artigo, será apresentando um resumo do filme, bem como uma problematização a respeito da internação compulsória e dos discursos sobre o uso de drogas, com o fim de refletir sobre a realidade atual e sobre a garantia de direitos de um grupo estigmatizado.

$\mathrm{Na}$ sequência, a análise das questões atinentes à internação compulsória será feita a partir de trechos da película, os quais também dão nome aos subitens que compõem o capítulo intitulado "projeção do "bicho de sete cabeças" para além das telas do cinema".

Este ensaio visa, portanto, evidenciar a problemática inerente ao assunto, que é uma realidade discutida, enfrentada e combatida por diversos países, organizações internacionais e comunidades científicas. Busca-se, assim, a partir de uma perspectiva interdisciplinar, agregar os conhecimentos atuais de diversas ciências para o 
enfrentamento das questões trazidas pelo longa-metragem em análise, o qual representa, ainda, a realidade pátria sobre o uso e o combate às drogas (e usuários).

\section{O FILME}

Baseado na história vivida por Austregésilo Carrano Bueno, "Bicho de Sete Cabeças" é uma obra cinematográfica nacional, lançada em 2001 e dirigida por Laís Bodanzky, que narra a internação de um jovem em um hospital psiquiátrico para o tratamento em decorrência de um suposto vício. O filme teve grande destaque, recebeu elogios pela crítica, além de indicações e prêmios nacionais (Prêmio Qualidade Brasil, o Grande Prêmio Cinema Brasil, Troféu APCA de "Melhor Filme", Festival de Brasília e Festival do Recife) e internacionais (Prêmio do Jovem Júri no 54º Festival de Locarno). Em 2015, o longa entrou na lista dos 100 melhores filmes brasileiros de todos os tempos, elaborada pela Associação Brasileira de Críticos de Cinema (Abraccine).

O personagem principal, Neto, interpretado por Rodrigo Santoro, é um jovem internado pelo pai, Wilson (Othon bastos), quando este encontra um cigarro de maconha junto a uma camiseta do filho deixada na sala da casa. A partir desse momento, sem nenhuma avaliação médica, o jovem é submetido à administração de medicamentos e procedimentos, como eletrochoque, que o expõe a uma situação desumana. Em meio a isso, Neto vivencia, em diversos momentos, o ódio pelo seu pai.

Após passar pela internação, o jovem não consegue retomar sua vida. Em diversas passagens agoniza relembrando os momentos de tortura a que foi submetido. A saída? Uma nova internação e uma tentativa de suicídio.

É de se ressaltar que, tecnicamente, a primeira modalidade de internação vivenciada pelo jovem é a involuntária, tendo em vista que foi determinada pela família. $\mathrm{Na}$ segunda vez, por outro lado, é determinada pelo Estado. Ao longo do artigo, contudo, a terminologia será sempre "internação compulsória", tendo em vista tal distinção nem se fazia presente à época do filme e que o elo comum que é enfrentado por este ensaio é o da decisão tomada contra a vontade do indivíduo - seja pelo Estado, seja pela família.

Diversas abordagens podem decorrer da riqueza de temas trazida pelo filme. Aqui, a opção será pela análise da internação compulsória, em cotejo com a tutela de direitos constitucionalmente assegurados, bem como dos discursos existentes sobre o 
uso de drogas, explicitadas pelo longa-metragem, e que favorecem a consolidação de realidades degradantes.

A investigação buscará sempre um movimento dialógico entre o filme e as questões jurídicas e sociais a serem enfrentadas. Dessa forma, sempre que artigo fizer menção a Neto e Wilson, a referência diz respeito aos personagens da película.

\section{DISCURSOS E CONSTRUÇÕES SOBRE O USO DE DROGAS}

Estudar temas relacionados ao uso de drogas traz, desde logo, o contato com inúmeros estereótipos, reproduzidos e reforçados por diversos meios - conversas cotidianas, representações midiáticas, projetos de lei, judicialização da saúde, etc. Um traço decorrente de políticas de caráter marcadamente proibicionista é a "demonização" das drogas, colocada como inimigo número um da sociedade, como risco iminente para a população e para a nação, o que leva a uma repressão constante em todos os meios. Neste sentido, Mota (2008) questiona: crime, pecado ou doença?

Esclarecendo tais construções, mencionado autor demonstra que para a maioria das religiões cristãs, aquele que faz uso de drogas é visto como um alguém que se desviou do projeto de Deus e, assim, escolheu o caminho do pecado "através da destruição de seu corpo, de sua espiritualidade e dos relacionamentos interpessoais" (MOTA, 2008, p. 22).

Já no âmbito jurídico, marcado pelo proibicionismo, que persiste no Brasil até os dias atuais, inobstante os dados concretos a respeito do fracasso desse tipo de política (MOTA, 2008), o usuário de drogas é visto como criminoso, como alguém que cometerá delitos em decorrência de seu vício e que usa substâncias proibidas por lei.

Por fim, o discurso médico é responsável pela construção social da dependência química como uma doença, o que fortaleceu a elaboração de tratamento e políticas públicas com foco na abstinência, e não no indivíduo, e também para a medicalização daqueles que fazem uso de determinadas substâncias, além de fortalecer o movimento de judicialização da saúde - notadamente pelas ações de internação compulsória.

Assim, algumas das construções sociais sobre o uso de drogas trazem consigo determinados estigmas, resultantes de um processo de manipulação simbólica, sempre ideológico, veiculados cotidianamente e que cria e mantém relações de dominação. Em 
suma, o contexto também é marcado pela categorização social, decorrente dos estigmas, e que leva à discriminação.

Nesta perspectiva, o estereótipo desempenha o papel de um filtro que altera a percepção dos outros, constituindo-se como a base cognitiva dos preconceitos, que designam o "julgamento a priori e geralmente negativo de que são vítimas os membros de certos grupos". Assim, por exemplo, são os relatos de uma roda de conversa: "um interlocutor afirma que as pessoas não "chegam” no usuário para ajudar, e só sabem dizer aquele lá é um drogado, aquele lá é um ladrão, aquele lá vai morrer... as pessoas não vêm assim passar uma mensagem pra frente, de conforto... '." (ROMANINI; ROSO, 2014, p. 981).

Diante disto, torna-se imperioso tomar consciência das construções sociais envolvidas neste tema, tendo em vista que tais discursos são meio para transformar o não familiar em familiar, tornar determinadas visões como naturais e verdadeiras, e, assim, rotular um comportamento que vai contra o entendimento comum. Dessa forma, o objetivo é salientar que tais narrativas, além de não serem decorrentes do mero acaso, são construções sociais e que trazem consigo grandes implicações políticas (MOTA, 2008).

O que se percebe, portanto, é que tais discursos ensejam um processo de abstração e de objetivação do sujeito em diversas esferas, pela padronização descritiva (REIS; GUARESCHI, 2014) e pela transformação do "corpo-pessoa" num corpo “objetificado" (ROMANINI; ROSO, 2014), o qual corrobora para o fortalecimento do estigma e para o abandono da apreensão do usuário de drogas enquanto sujeito.

Dentre as categorizações presentes na abordagem do assunto, as mais comuns são a do usuário de drogas enquanto um risco a si mesmo e à sociedade; como mortosvivos desprovidos de razão (WURDIG; MOTTA, 2014) e como criminosos $^{3}$; discursos estes que corroboram para a falta de questionamento e preocupação com o tratamento adequado de tais sujeitos.

Assim, o presente ensaio objetiva, por meio de uma conversa contínua com o longa-metragem "Bicho de Sete Sabeças", discorrer sobre o modo como determinados

\footnotetext{
3 "Este pano de fundo de indefinições quanto aos critérios que classificam usuário e traficante, e a própria situação de uso, que por si só coloca o indivíduo em condição desviante por ser objeto de estigmatização e criminalização, dá margem à criação de um estereótipo de suspeito, muitas vezes associado ao estigma de indivíduo agressivo e perigoso, o que tem relação estreita com o conceito de "sujeição criminal" (...). (TOLEDO; GONGORA; BASTOS, 2017).
} 
discursos atrelados ao fenômeno das drogas corroboram para a construção social de rótulos e estereótipos relacionados a esta "forma particular de transgressão" (MOTA, 2008) e que culminam na legitimação de "políticas" como a da internação compulsória, tendo em vista "que uma representação não é redutível a seus aspectos cognitivos e avaliativos: simultaneamente expressiva e construtiva do social, consiste não somente num meio de conhecimento, mas em um instrumento de ação" (LAPLANTINE, 2001, pp. 241-242).

\section{A INTERNAÇÃO COMPULSÓRIA}

A realidade brasileira é marcada pela discussão sobre a internação compulsória como forma de tratamento para dependentes químicos e também pela sua utilização como o principal meio para lidar com os usuários de drogas. Dessa forma, a internação não se configura como uma medida excepcional, tal como previsto na Lei de Reforma Psiquiátrica, mas como uma nova prática que precisa ser discutida.

Apesar da generalização dessa medida no cenário nacional, deve-se ressaltar que a Organização Mundial da Saúde (OMS) propõe como meta a remoção da atenção dos grandes hospitais psiquiátricos, com o escopo de fortalecer o tratamento e a atenção com base comunitária, convertendo os hospitais em centros de tratamento ativo e de reabilitação (OMS, 2001). No relatório sobre Neurociência e a dependência, conclui-se que a pesquisa em neurociências levou ao desenvolvimento de diversas formas de tratamento com foco em intervenções farmacológicas e comportamentais, sendo que a internação não aparece como proposta em nenhum momento (OMS, 2004).

$\mathrm{Na}$ mesma linha, o Relator da Organização das Nações Unidas, para o Enfrentamento à Tortura, Juan E. Mendez (2013), em relatório apresentado ao Conselho de Direitos Humanos, sinalizou que as internações compulsórias podem configurar formas de tortura. Ademais, estudos qualitativos verificaram que a perda da autonomia e da autoestima, bem como fortes reações emocionais, tais como sentir-se desvalorizado, estigmatizado e desumanizado são consequências comuns da internação compulsória (RÜSCH, 2014).

O problema torna-se ainda mais grave quando se leva em conta uma realidade em que os serviços de saúde são pautados pelo lucro e em que muitas instalações em que ocorre a internação não possuem adequação para tal, constituindo-se apenas em 
“depósito desumanizado de pacientes, funcionando como elemento intensificador de doenças." (MIGUEL; FRANÇA, 2001). No mesmo sentido, existem "clínicas” que anunciam em seus sites a realização de internação compulsória e até mesmo de "resgates", mesmo sem qualquer autorização judicial para que o referido "serviço" seja prestado.

Neste sentido, existem estudos que relacionam as medidas de internação com uma política midiática e simbólica, que tem por fim satisfazer interesses econômicos e políticos, promovendo uma exclusão social e tornando invisível este grupo estigmatizado, a fim de ocasionar uma falsa sensação de segurança e de se estar tutelando a saúde, quando, na verdade, se está excluindo do espaço público um grupo social que o Estado deveria proteger, a fim de concretizar os direitos sociais previstos na Constituição Federal e assegurar o exercício da cidadania (PÊCEGO; NETO, 2014).

O que se percebe, portanto, é que a internação se torna uma medida generalizada. O que existe, na verdade, é uma "política de exceção", tal como afirmado por Denis Petuco, cientista social e mestre em educação pela UFJF, no documentário "Crack, repense". No mesmo documentário, Dartiu Xavier, psiquiatra livre docente da UNIFESP, afirma que de todos os dependentes químicos, menos de 5\% teria a indicação de uma internação voluntária e que, para a involuntária, tal indicação é de menos de $1 \%$.

\section{PROJEÇÃO DO "BICHO DE SETE CABEÇAS" PARA ALÉM DAS TELAS DO CINEMA}

Quase duas décadas depois de seu lançamento, e algumas mais da histórica vivenciada por Carrano, o cenário narrado parece o mesmo dos dias atuais. Apesar das mudanças legislativas que preconizam a internação compulsória como medida excepcional e que criam um rol de direitos a serem assegurados, as denúncias e discussões da realidade contemporânea brasileira parecem uma projeção de "Bicho de Sete Cabeças" para além das telas do cinema. A partir disso, inicia-se uma análise, em que cada subitem tem como título uma passagem retirada do filme, e em que se intercalam trechos do longa-metragem com estudos, dados e questionamentos presentes no cenário atual. Nesse sentido, as menções a Neto e Wilson são sempre referências aos personagens da película. 
4.1. "VOU VISITAR UM AMIGO MEU QUE FOI HOSPITALIZADO, VOC $\hat{\text { }}$ VEM COMIGO?".

Tudo começa quando, com o pretexto de visitar um amigo hospitalizado, Wilson leva o filho para o hospital psiquiátrico. Ao chegar, Neto é carregado de forma truculenta pelos funcionários da instituição. Sem entender nada, vem a explicação: "seu pai acha que você é viciado e trouxe você aqui para fazer um tratamento". Neto, então, responde "de vez em quando eu fumo, mas eu não sou um viciado". Todavia, sem espaço para qualquer deliberação, a sentença está dada: "seu pai disse que você é".

Sem qualquer exame ou avaliação médica e sem nenhuma informação sobre os procedimentos, o "tratamento" tem início com a administração de remédios para manter o "viciado" "calmo e tranquilo". Desesperado com a situação, Neto conversa com outros internos, dentre eles, Rogério (Caco Ciocler) e afirma que irá fugir dali. A resposta apresentada por alguém que já conhece melhor a realidade que enfrentam é clara: "não dá pra fugir daqui não, isso aqui é pior que prisão!".

Assim, com o fim de manter Neto aprisionado, mesmo sem qualquer diagnóstico ou avaliação do interno, o diagnóstico é dado aos familiares: "dependência de drogas e distúrbio de personalidade”. O quadro cénico mostra uma realidade que não pode passar despercebida: além de todas as discussões sobre a efetividade ou não da internação compulsória para o tratamento de dependentes químicos, a medida passa a ser usada também para meros usuários, ainda que o quadro clínico que caracteriza a dependência, enquanto doença, não esteja presente.

Nesse sentido, Dartiu Xavier, ao ser questionado a respeito do risco de internações de pessoas que não são dependentes, assevera acreditar que esta seja a regra: "só a presença do crack já faz com que a pessoa seja vista como alguém precisa ser internada, quando isso não é verdade.” (ROUSSELET, 2013). O psiquiatra, em outra oportunidade, relata que as taxas de recaída após uma internação compulsória são de 95\%, sendo que os melhores resultados são obtidos pelos tratamentos ambulatoriais. Assim, questiona: "se a internação compulsória não é a melhor maneira de tratar um dependente, o que dizer de sua utilização no caso de usuários, não de dependentes?". Ato contínuo, afirma: "a dependência de drogas não se resolve por decreto". 


\section{2. "A GENTE VAI EMBAIXO DE ALGUM VIADUTO AI E CONSEGUE UM MONTE dE INTERNAÇÃo. A GENTE NÃO PODE É PERDER ESSE REPASSE DO GOVERNO.”.}

- "472 internos exatamente”;

$-(\ldots)$

- “É, não, isso não empata nada não. A gente chega aos 500 se o problema for este. A gente vai embaixo de algum viaduto ai e consegue um monte de internação. A gente não pode é perder esse repasse do governo.".

O trecho transcrito relata uma conversa do personagem Dr. Araújo (Altair Lima) ao telefone. Transpondo o diálogo para o cenário atual, deve-se retomar a questão da busca pelo lucro na área de saúde, anteriormente apresentada. Além disso, uma das consequências das políticas proibicionista é o fortalecimento de determinados grupos de poder, dentre os quais instituições especialistas na realização deste tipo de tratamento.

Assim, tendo em vista a concretização de uma "política de exceção" no que diz respeito às internações, fica o questionamento se o discurso protagonizado pelo psiquiatra do filme não é reproduzido na realidade social, camuflado por práticas discursivas que visam legitimar e massificar tal medida. Neste sentido, o Ministério Público do Estado de São Paulo apurou que no ano de 2013 foram realizadas 5.335 internações involuntárias de usuários de drogas. Em relação a 2003, houve um aumento de $600 \%$ do número de internações.

Dessa forma, se as clínicas particulares podem realizar resgastes e internar pessoas, mesmo contra a vontade delas, recebendo, ainda, recursos públicos, a tendência é de aumento dos lucros e consequente mercantilização de serviços de saúde. Ainda que não sejam os viadutos: as cracolândias são os novos alvos para conseguir "um monte de internação" - o que atende aos interesses do governo e da sociedade de não ter a miséria do seu campo de visão. Assim, por exemplo, são as manchetes que elucidam as políticas do prefeito de São Paulo: "Doria Jr. quer "erradicar" cracolândia com internação obrigatória" 4 .

Com a mesma ideologia, em 2013 o governo do estado de São Paulo propôs o "bolsa-crack" ou, ainda mais convincente, "cartão do recomeço", com o fim de

\footnotetext{
4 Disponível em: < http://jovempan.uol.com.br/noticias/brasil/sao-paulo/pre-candidato-doria-jr-quererradicar-cracolandia-com-internacao-obrigatoria.html>. Acesso em: 01 maio 2017.
} 
estruturar uma política pela qual seria concedido determinado montante para custear a internação dos usuários de drogas em clínicas particulares especializadas.

Em consonância com o exposto também são os projetos de lei nacionais: o Projeto de Lei 2074, de 2015, por exemplo, visa instituir o "Programa Nacional de Recuperação de Dependentes Químicos", o qual tem como finalidade "a criação, ampliação e articulação de centros exclusivos para atendimento às pessoas com necessidades de internação voluntária, involuntária ou compulsória (...).”. O Projeto de Lei 5.251, de 2016, por sua vez, tem como objetivo "tornar obrigatória a internação de dependentes químicos (...).”.

\section{3. “DROGA NÃO, REMÉdIO! DROGA É O QUE VOCÊ TOMAVA LÁ FORA".}

Na primeira visita familiar, cegos por uma série de construções que objetivam garantir a internação de diversas pessoas, a família não consegue ver o que Neto enfrenta. Os comentários são sobre como ele está mais forte e deixou de ter a magreza de aidético; sobre a beleza e paz do jardim e sobre como o Dr. Araújo é um dos maiores psiquiatras do Brasil.

Por trás dessas construções, contudo, a realidade é bem diferente. O ganho de peso decorre de remédios administrados para aumentar o apetite e garantir uma aparência mais saudável perante a família, para que ninguém acredite nos relatos dos internos, como alertado pelo personagem de Caco Ciocler. O jardim, por sua vez, é apenas a fachada de um lugar sem qualquer estrutura, higiene e condições dignas para um tratamento humano e eficaz. O grande psiquiatra, por fim, faz uso de drogas dentro do seu próprio consultório.

Além disso, ao relatar que "está sendo entupido de droga", Neto escuta do pai que droga era o que ele usava lá fora. Tal fala traz à tona as construções sociais a respeito das drogas, em que tal termo se associa, imediatamente, àquelas consideradas ilícitas. Este fato mostra que o proibicionismo é algo natural no imaginário social, tendo em vista que ninguém se questiona como/porque ele existe, consolidando-se um axioma sobre porque algumas drogas devem ser ilícitas e outras não (MOTA, 2008).

Dessa forma, Wilson afirma categoricamente: “droga não, remédio!”. Neste ponto, frisa-se a atuação das agências farmacêuticas, que lucram ao substituir o uso de 
psicoativos tido como ilícitos por remédios de sua produção, fato esse que reflete um processo histórico, em que as drogas industrializadas foram patenteadas e passaram a ocupar o espaço de substâncias naturais que passaram a ser perseguidas (MOTA, 2008) 5

O que se percebe, assim, é que o critério para a ilegalidade de determinada droga não é o seu "potencial farmacológico de destruição" (como faz crer o discurso dominante), mas sim outros interesses de cunho político e econômico. Como consequência disso, nos Estados Unidos (EUA) o número de pessoas usando substâncias psicoativas legais (antidepressivos, estimulantes ou estabilizadores de humor) triplicou no período de 10 anos (KENNEDY apud MOTA, 2008, p. 120).

O exposto evidencia a ambiguidade da classificação lícito/ilícito e mostra outro ponto implícito ao proibicionismo, que é o seu uso enquanto meio para intensificar a exclusão social de determinados grupos, como negros, jovens pobres, imigrantes, etc. (MOTA, 2008) ${ }^{6}$.

Ademais, ao contrário do que faz crer as práticas discursivas a respeito das drogas ilícitas, outro efeito constatado pelos estudos que verificam os impactos do proibicionismo é o fortalecimento do crime organizado, de modo que a política instaurada não é hábil para resolver o problema das drogas, tendo em vista que o capital decorrente do narcotráfico é lavado em atividades "lícitas", mantendo impunes os responsáveis, que são tidos como respeitáveis membros da sociedade (MOTA, 2008) ${ }^{7}$.

\footnotetext{
${ }^{5}$ A disputa, em linhas gerais, estava em torno da seguinte questão: os Estados industrializados (EUA e países da Europa ocidental) exigiam maior rigidez no controle de opiáceos, maconha e cocaína e pouca regulação para os psicoativos sintéticos (barbitúricos e anfetaminas) produzidos em suas indústrias farmacêuticas, ao passo que os países menos desenvolvidos, produtores principalmente de ópio bruto e folhas de coca, defendiam sua posição e, em caso de proibição total dos psicoativos, a inclusão também das drogas sintéticas na lei internacional. O impulso proibicionista parecia dirigir-se para os psicoativos tradicionais, e não para as novas drogas devidamente patenteadas e que ocupariam o espaço a ser deixado pelas substâncias perseguidas. (Rodrigues, 2003:37)

6 "Na realidade, existe pouca diferença entre um bebedor social e alguém que fuma um cigarro de maconha, somente o fato de que o segundo está usando uma substância ilegal. Quando um médico receita, legalmente, Ritalina para "apaziguar" uma criança hiperativa ou um tranquilizante para uma dona de casa "estressada", o intuito é quase o mesmo daquela pessoa que busca relaxamento através da Cannabis. Entretanto, a condenação moral e penal que recai sobre os usuários de drogas ilícitas faz com que sua estigmatização seja bem maior, propiciando seu engajamento em "subculturas" relacionadas a delitos que coexistem no universo segregado da venda ilegal de drogas. A criminalização de determinadas substâncias cria marginalidade em torno delas, ou seja, a figura do drogado é uma construção social das políticas oficiais de enfrentamento do consumo de drogas específicas" (MOTA, 2008).

${ }^{7}$ De maneira geral, o maior montante do dinheiro do tráfico de drogas não fica nas favelas. Caso assim o fosse, a Colômbia seria uma espécie de Suíça latino-americana e as favelas do Rio de Janeiro condomínios de luxo. Na realidade, as populações pobres que estão na "linha de frente" do tráfico não
} 
O resultado disto é que apenas 5 a $10 \%$ da produção mundial de drogas ilícitas é apreendida, inobstante os bilhões de dólares gastos para tal fim (MAIEROVITCH apud MOTA, 2008, p. 120). Ademais, enquanto o orçamento é gasto no combate ao tráfico, o comércio ilegal gera o aumento do número de homicídio: no Brasil de 8,67 para 59 por 100 mil habitantes; em São Paulo aumentou 465\% entre 1980 e 1998, enquanto o número de óbitos naturais subiu apenas 19\% (TEIXEIRA apud MOTA, 2008, p. 120).

Além disso, a construção sobre uso de drogas ilícitas e crimes também é duvidosa, pois a maioria dos delitos se relaciona a disputa por pontos de drogas, enquanto que o número de crimes brutais cometidos se relaciona em grande medida com o álcool. E, como consequência disso, o sujeito é levado ao sistema penal, que não tem capacidade de recuperação e reinserção do indivíduo na sociedade.

Todo o cenário é permitido pelo apoio da opinião pública, inexistindo um entendimento de que o tráfico e suas consequências só existem por conta do proibicionismo. Não existe um questionamento a respeito da realidade existente. Assim, algumas reflexões tornam-se importante, tais como: "se uma substância como a maconha é capaz de produzir 162 milhões de transgressores no mundo, será que não existe incoerência nesta proibição?”; "Se os atos violentos associados ao uso de substâncias psicoativas estão muito mais relacionados ao uso de álcool do que a qualquer outra substância ilegal, porque persiste a proibição da maconha?" (MOTA, 2008, p. 132).

\section{4. "ME TIRA DAQUI! ME TIRA DAQUI!"}

$\mathrm{Na}$ segunda visita do pai, após a submissão ao "tratamento" com diversos medicamentos e a experiência do eletrochoque, decorrente de uma tentativa de fuga, a única fala de Neto, que se repete, mesmo ante a evidente falta de força do personagem, é: “me tira daqui!". Um verdadeiro grito de socorro proclamado na forma de um sussurro. O pai, então, atende ao pedido. Já em casa, o protagonista agoniza em meio às memórias e os traumas vivenciados no período em que esteve internado.

Aqui é imperioso o debate acerca de uma das categorizações decorrentes dos estereótipos que recaem sobre o usuário de drogas: o de morto- vivo e zumbi- "os

trabalham para si, mas para enriquecer outros agentes que certamente não residem nessas "áreas de risco" (ZALUAR, 2004). 
usuários de crack estão se multiplicando e vemos verdadeiros mortos-vivos circulando, pessoas que não tem autoconsciência. Precisamos tirar esses zumbis, que criam cracolândias por todo Brasil, da rua." (internação involuntária é a compaixão que a sociedade deve ter com seus filhos apud WURDIG; MOTTA, 2014).

Tão forte e presente é este discurso na realidade brasileira que o documentário "Crack, repense", de uma forma crítica, tem inicio com a representação dos ditos "zumbis": "Como eu virei zumbi? Foi assim, ó: pedrinhas de crack.".

O filme Bicho de Sete Cabeças, por sua vez, deixa implícito o questionamento: o que, de fato, transforma o sujeito em um zumbi? O sofrimento, os traumas e a debilidade de Neto (protagonista da película), vivenciados após a internação, deixa claro que é o tratamento segregador e desumano, e não o uso de drogas.

$\mathrm{E}$, antes de qualquer argumento no sentido de que é apenas uma ficção cinematográfica, a $4^{\mathrm{a}}$ Inspeção Nacional de Direitos Humanos, a respeito dos locais de internação para usuários de drogas, realizada pelo Conselho Federal de Psicologia (2011), deixa evidente a situação alarmante de violação de direitos humanos.

Assim, as conclusões do relatório são no sentido de que "a pergunta que nos orientou - sobre a ocorrência de violação de direitos humanos - infelizmente se confirmou como uma regra", existindo "claros indícios de violação de direitos humanos em todos os relatos" (CONSELHO FEDERAL DE PSICOLOGIA, 2011, p. 190).

Para deixar claro, dentre inúmeras outras violações de direitos constitucionalmente assegurados a todos os indivíduos, a inspeção relatou um grande capítulo de maus-tratos, violência física e humilhações. A prática de tortura é ilustrada com alguns exemplos: "internos enterrados até o pescoço (recurso terapêutico?); o castigo de ter de beber água de vaso sanitário por haver desobedecido a uma regra ou, ainda, receber refeições preparadas com alimentos estragados" (CONSELHO FEDERAL DE PSICOLOGIA, 2011, p. 191). No mesmo sentido são as práticas de laborterapia, que assumem caráter análogo ao trabalho escravo (CONSELHO FEDERAL DE PSICOLOGIA, 2011, p. 192).

\section{5. “AGORA VOCÊ VAI TER QUE ME OUVIR".}

Consequência de todo o exposto e das estigmatizações que recaem sobre os usuários de drogas é a concepção do indivíduo como alguém privado de capacidade de 
autodeterminação, o que legitima que terceiros tomem decisões a respeito de sua vida, determinando, por exemplo, a submissão a uma internação. É difícil, contudo, afirmar a ausência de tal capacidade quando, em diferentes espaços da vida social, a voz de tais sujeitos não é levada em conta.

Neste sentido, por exemplo, um artigo que realizou análise de conteúdo de diversas notícias jornalísticas sobre a internação compulsória, constatou que em apenas um caso existiu a preocupação com o discurso do usuário ou da família. Apesar disso, a exposição se deu de maneira sensacionalista - provavelmente com o fim de corroborar o tipo de discurso veiculado em outras reportagens (WURDIG; MOTTA, 2014, p. 443).

Ademais, a impessoalidade aparece como marca comum no modo como se trata o usuário de drogas, demonstrando o processo de coisificação do sujeito, relatado como "morto-vivo", o que "faz com que nem se reflita acerca do tipo de serviço que será disponibilizado para ele”, pois “estamos falando de 'zumbis'(...) que não necessitam de um atendimento humanizado ou de algum cuidado, mas que sejam retirados, enfrentados, para que parem de assustar as pessoas nas ruas." (WURDIG; MOTTA, 2014, p. 440).

É diante desse massacre ao indivíduo e do sufocamento a que ele é submetido, que Neto escreve ao pai: "Pai, as coisas ficam muito boas quando a gente esquece, mas eu não esqueci o que você fez comigo, eu não esqueci a sua covardia. Agora você vai me ouvir: tô te mostrando a porta da rua pra você sair sem eu te bater.”.

A finalidade deste ensaio é, justamente, reforçar o "agora você vai ter que me ouvir", apresentando alguns dos discursos e construções sociais que existem quando o assunto é drogas para, assim, questionar as consequências que decorrem dessas construções e, além disso, promover uma desconstrução, tendo em vista as possibilidades trazidas por outros discursos, os quais parecem se ajustar melhor quando o foco é uma tutela efetiva de direitos dos indivíduos.

\section{CONCLUSÕES}

O cenário narrado pelo filme, que retrata uma história de vida, é também a realidade atual. Relatos, denúncias e inspeções demonstram, reiteradamente, a opção por uma política que enseja a violação de direitos humanos. A Lei de Reforma Psiquiátrica, que disciplina as internações, as definem como medida excepcional. 
Todavia, o que se concretiza é uma "política de exceção", na qual o que deveria ter caráter extraordinário se tornou generalizado.

O enfrentamento da questão, à luz do ordenamento jurídico brasileiro, torna imperiosa algumas reflexões. A Constituição Federal traz a dignidade humana e a cidadania como parte de seus fundamentos. Seu artigo quinto traz um extenso rol de direitos que se aplicam (em tese) a todos os indivíduos. Esses direitos são reforçados pela Lei de Reforma Psiquiátrica e pelos inúmeros projetos de lei que visam ampliar a internação dos usuários de drogas.

Liberdade? Como é possível falar em liberdade em um cenário no qual a pessoa não tem ciência sobre o tratamento a que será submetida, em que seu consentimento não é colhido e em que sua vontade não tem nenhuma importância? Integridade física e psíquica? Como é possível se referir a tais direitos quando a política pública adotada concretiza medidas de tortura, tratamentos degradantes e alienação do sujeito? Saúde? Como é possível falar em saúde se a medida adotada não recupera, não reinsere e, na verdade, causa mais prejuízos que benefícios? Cidadania? Como falar em cidadania quando se promove exclusão e segregação de grupos "indesejados" socialmente? Afinal, que dignidade é essa? Ela também vale para minorias categorizadas por tantos estereótipos?

Como consequência do contexto narrado, o que se percebe, portanto, é a consolidação da internação compulsória, não como medida excepcional, mas como prática corriqueira, e de uma lógica de padronização descritiva, de controle de comportamentos e de um discurso de garantia de direitos que, em verdade, culmina na desproteção e no fortalecimento dos estigmas.

Diante da constatação dessa realidade - em diferentes âmbitos - é que os estudos chamam atenção para a necessidade de encontros dialógicos que fomentem debates e criem processos de singularização que permitam a elaboração de políticas públicas e de escolha de tratamentos livre de estereótipos e preconceitos que estigmatizam os usuários de substâncias psicoativas, sob pena de consolidação de práticas higienistas.

\section{REFERÊNCIAS BIBLIOGRÁFICAS}

BRASIL. Câmara dos Deputados. Projeto de Lei $\mathbf{n}^{\mathbf{0}}$ 2.704, de 2015. Institui o Programa Nacional de Recuperação de Dependentes Químicos. Disponível em: 
<http://www.camara.gov.br/proposicoesWeb/prop_mostrarintegra?codteor $=1374088 \& \mathrm{f}$ ilename $=\mathrm{PL}+2704 / 201>$. Acesso em: 01 maio 2017

Câmara dos Deputados. Projeto de Lei no 5.251, de 2016. Torna obrigatória a internação de dependentes químicos que não tenham familiares em estabelecimentos de saúde autorizados. Disponível em: <http://www.camara.gov.br/sileg/integras/1460270.pdf>. Acesso em: 01 maio 2017.

CONSELHO FEDERAL DE PSICOLOGIA. Relatório da $4^{\text {a }}$ Inspeção Nacional de Direitos Humanos: locais de internação para usuários de drogas. Brasília: Conselho Federal de Psicologia, 2011. Disponível em: < https://site.cfp.org.br/wpcontent/uploads/2012/03/2a_Edixo_relatorio_inspecao_VERSxO_FINAL.pdf>. Acesso em: 01 maio 2017.

GUARESCHI, Neuza Maria de Fátima; LARA, Lutiane de; ECKER, Daniel Dall'Igna. A internação compulsória como estratégia de governamentalização de adolescentes usuários de drogas. Estud. psicol. (Natal), Natal, v. 21, n. 1, p. 25-35, 24 Mar. 2016. Disponível em <http://www.scielo.br/scielo.php?script=sci_arttext\&pid=S1413294X2016000100025\&lng=en\&nrm=iso>. Acesso em 31 Mar. 2017.

JORGE, Miguel R; FRANCA, Josimar MF. A Associação Brasileira de Psiquiatria e a Reforma da Assistência Psiquiátrica no Brasil. Rev. Bras. Psiquiatr., São Paulo , v. 23, n. 1, p. 3-6, Mar. 2001 . Disponível em $<$ http://www.scielo.br/scielo.php?script=sci_arttext\&pid=S1516-

$44462001000100002 \& \operatorname{lng}=\mathrm{en} \& n r m=$ iso>. Acesso em 01 May 2017

LAPLANTINE, François. Antropologia dos sistemas de representações da doença: sobre algumas pesquisas desenvolvidas na França contemporânea reexaminadas à luz de uma experiência brasileira. In: JODELET, Denise (org.). As representações sociais. Rio de Janeiro: Ed. UERJ, 2001.

LARANJEIRA, Ronaldo. Legalização de drogas e a saúde pública. Ciênc. saúde coletiva, Rio de Janeiro, v. 15, n. 3, p. 621-631, May 2010 . Disponível em $<$ http://www.scielo.br/scielo.php?script=sci_arttext\&pid=S1413-

$81232010000300002 \& \operatorname{lng}=\mathrm{en} \& n r m=$ iso $>$. Acesso em 31 Mar. 2017.

MENDEZ, Juan E. Report of the Special Rapporteur on torture and other cruel, inhuman or degrading treatment or punishment. Genebra: United Nations, 2013.

MOSCOVICI, Serge. Representações sociais: investigações em psicologia social. Petrópolis/RJ: Vozes, 2003.

MOTA, L. A. Pecado, crime ou doença? Representações sociais da dependência química. $246 \mathrm{f}$. Tese (doutorado em sociologia). Universidade Federal do Ceará: Fortaleza, 2008. 
OMS (Orgs.). Relatório sobre a saúde no mundo. Saúde Mental: nova concepção, nova esperança. . Disponivel em: <http://www.abebe.org.br/wpcontent/uploads/oms2001.pdf>. Acesso em: 10 maio 2016, p. 88.

Organização Mundial da Saúde (Orgs.). Neurociências: consumo e dependência de substâncias psicoativas. Genebra: OMS, 2004. Disponível em: $\langle$ http://www.who.int/substance_abuse/publications/en/Neuroscience_P.pdf $>$. Acesso em: 10 maio 2016.

PÊCEGO, Antonio José F. de; NETO, Zaiden Geriage. Crack: internação compulsória e cidadania. Disponível em: < http://www.ajuris.org.br/OJS2/index.php/REVAJURIS/article/view/291>. Acesso em: 10 maio 2016.

PINTO, Leila de Oliveira; OLIVEIRA, Daniele Jesus de; DUARTE, Fabia Maria Ribeiro. Grupo Informativo: estratégia de redução de danos para pessoas apreendidas por consumo/porte de drogas ilícitas. Interface (Botucatu), Botucatu , v. 19, supl. 1, p. 965-973, 2015. Disponível em <http://www.scielo.br/scielo.php?script=sci_arttext\&pid=S1414-

32832015000500965\&lng=en\&nrm=iso >. Acesso em 31 Mar. 2017.

REIS, Carolina dos; GUARESCHI, Neuza Maria de Fátima; CARVALHO, Salo de. Discursos sobre Família e Risco nas Internações Compulsórias de Usuários de Drogas.

<http://revistaseletronicas.pucrs.br/ojs/index.php/revistapsico/article/view/19388>.

Acesso em 24 Mar. 2017.

Sobre jovens drogaditos: as histórias de ninguém. Psicol. Soc., Belo Horizonte , v. 26, n. spe, p. 68-78, 2014. Disponível em $<$ http://www.scielo.br/scielo.php?script=sci_arttext\&pid=S0102-

$71822014000500008 \& \operatorname{lng}=$ en\&nrm=iso>. Acesso em 25 Mar. 2017.

ROMANINI, Moises; ROSO, Adriane. Midiatização do crack e estigmatização: corpos habitados por histórias e cicatrizes. Interface (Botucatu), Botucatu, v. 18, n. 49, p. 363-376, Julho 2014. Disponível em $<$ http://www.scielo.br/scielo.php?script=sci_arttext\&pid=S1414-

32832014000200363\&lng=en\&nrm=iso>. Acesso em 25 Mar. 2017. Epub Mar 17, 2014.

ROUSSELET, Felipe. Dependência química: internação é solução? Fórum. 2013. Disponível em: <http://www.revistaforum.com.br/2013/09/30/internacao-e-solucao/>. Acesso em: 01 maio 2017.

Dartiu Xavier: "Internação Compulsória seria Inaceitável em Países de Primeiro Mundo". 2015. Disponível em: < http://spressosp.com.br/2013/01/24/dartiu-xavier-internacao-compulsoria-seriainaceitavel-em-paises-de-primeiro-mundo/> . Acesso em: 01 maio 2017. 
RÜSCH, Nicolas (et. al). Emotional reactions to involuntary psychiatric hospitalization and stigma-related stress amon people with mental illness. Eur Arch Psychiatry Clin Neurosci (2014). Disponível em: < http://link.springer.com/article/10.1007/s00406-0130412-5\#page-1>. Acesso em: 12 maio 2016.

SCISLESKI, Andrea Cristina Coelho; MARASCHIN, Cleci. Internação psiquiátrica e ordem judicial: saberes e poderes sobre adolescentes usuários de drogas ilícitas. Psicol. estud., Maringá , v. 13, n. 3, p. 457-465, Sept. 2008 . Disponível em <http://www.scielo.br/scielo.php?script=sci_arttext\&pid=S1413$73722008000300006 \& \operatorname{lng}=$ en\&nrm=iso>. Acesso em 24 Mar. 2017.

SILVEIRA, Dartiu Xavier da. Dependência não se resolve por decreto. Disponível em: < http://adepolrj.com.br/adepol/noticia_dinamica.asp?id=9835>. Acesso em: 01 maio. 2017.

TOLEDO, Lidiane; GONGORA, Andrés; BASTOS, Francisco Inácio P. M.. À margem: uso de crack, desvio, criminalização e exclusão social - uma revisão narrativa. Ciênc. saúde coletiva, Rio de Janeiro, v. 22, n. 1, p. 31-42, Jan. 2017. Disponível em <http://www.scielo.br/scielo.php?script=sci_arttext\&pid=S141381232017000100031\&lng=en\&nrm=iso>. Acesso em 25 Mar. 2017.

WURDIG, Karolina Kuhn; MOTTA, Roberta Fin. Representações midiáticas da internação compulsória de usuários de drogas. Temas psicol., Ribeirão Preto , v. 22, n. 2, p. 433-444, dez. $2014 \quad$ Disponível em <http://pepsic.bvsalud.org/scielo.php?script=sci_arttext\&pid=S1413389X2014000200014\&lng=pt\&nrm=iso >. Acesso em 25 mar. 2017. 